\title{
Cheese consumption prevents fat accumulation in the liver and improves serum lipid parameters in rats fed a high-fat diet
}

\author{
Satoshi Higurashi ${ }^{1}$ - Akihiro Ogawa ${ }^{1}$ Takayuki Y. $\operatorname{Nara}^{1} \cdot$ \\ Ken Kato $^{1}$ - Yukio Kadooka ${ }^{1}$
}

Received: 12 November 2015 / Revised: 25 March 2016 / Accepted: 29 March 2016 /

Published online: 13 April 2016

(C) INRA and Springer-Verlag France 2016

\begin{abstract}
Cheese consumption has been reported to reduce the risk of metabolic syndrome; however, the mechanisms by which cheese prevents these disorders are not fully understood. The purpose of this study was to examine the effects of cheese consumption on lipid accumulation in the liver as well as to evaluate various serum lipid parameters. Two groups $(n=7)$ of male Fischer-344 rats were fed the following high-fat diets for 9 weeks: AIN76-modified 20\% fat diet containing casein and butter oil (control diet) or the $20 \%$ fat diet containing a freeze-dried cheese powder (cheese diet). Blood samples, liver tissue, and fecal specimens were collected and analyzed. Cheese consumption for 9 weeks reduced the accumulation of triglyceride and cholesterol in the liver $(P=0.016$ and $P<0.001$, respectively), as well as the serum non-highdensity lipoprotein (non-HDL) cholesterol concentration $(P=0.013)$. In contrast, cheese consumption increased the serum HDL concentration with statistical tendency $(P=0.086)$. We also observed an increase in the serum adiponectin concentration at week 9 in rats fed the cheese diet $(P=0.029)$. Furthermore, cheese consumption also increased fat excretion in the feces $(P<0.001)$. Taken together, our results suggest that cheese mediates various beneficial effects for preventing the development of metabolic syndrome by suppressing the accumulation of fat in the liver.
\end{abstract}

Keywords Cheese $\cdot$ Metabolic syndrome $\cdot$ Liver fat $\cdot$ Rats

Satoshi Higurashi

s-higurashi@meg-snow.com

1 Milk Science Research Institute, Megmilk Snow Brand Co. Ltd., 1-1-2 Minamidai, Kawagoe, Saitama, Japan 


\section{Introduction}

Due to high amounts of saturated fat and cholesterol present in dairy products, it is often recommended that the consumption of these products should be limited in order to reduce the risk of cardiovascular disease. However, a comprehensive meta-analysis of recent epidemiological studies suggests that ingestion of dairy products does not affect the risk of cardiovascular disease or may be inversely associated with the risk (Elwood et al. 2010; Larsson et al. 2015; Soedamah-Muthu et al. 2011). In fact, cheese, while known to be a high-fat dairy product, has been shown to induce various healthpromoting effects in several studies. For example, European countries with high cheese consumption, such as France, Switzerland, and Greece, also appear to have a lower incidence of cardiovascular disease and mortality (Petyaev and Bashmakov 2012). However, the full health benefits of cheese consumption and the underlying physiological mechanisms responsible for these effects are largely unknown.

Recently, cross-sectional analyses from the Oslo Health Study demonstrated that an increase in the frequency of cheese consumption was positively associated with the serum concentration of high-density lipoprotein (HDL) cholesterol and inversely associated with the serum triglyceride levels (Høstmark et al. 2009). Furthermore, cheese intake also appears to lower the level of low-density lipoprotein (LDL) cholesterol in the blood in human intervention studies (Biong et al. 2004; Hjerpsted et al. 2011; Nestel et al. 2005). Taken together, it seems likely that the health benefits of cheese may be mediated via improved cholesterol metabolism. In fact, a decrease in very low-density lipoprotein (VLDL) secretion was also reported in rats fed a high-fat diet containing cheese (Higurashi et al. 2007), suggesting that these cheese-induced changes in lipid metabolism could be occurring primarily in the liver, given that VLDL is synthesized and secreted from this tissue (Kang and Davis 2000). Thus, in the present study, we sought to evaluate the effect of cheese consumption on lipid accumulation in the liver as well as their secretion into the serum in rats fed a high-fat diet containing cheese.

\section{Materials and methods}

\subsection{Diet materials}

Isocaloric experimental diets containing 20\% fat were prepared using the components listed in Table 1. The Gouda cheese used in this study was produced by Megmilk Snow Brand (Tokyo, Japan) at their Nakashibetsu plant using Lactobacillus helveticus, a starter culture with a high protease activity, and was ripened for 8 months. Cheese samples were then freezedried and pulverized using a coffee mill in our laboratory. The amounts of protein (calculated from the total nitrogen content determined by Kjeldahl analysis), fat (acid hydrolysis method), carbohydrate (subtracting the weight of protein, fat, moisture, and ash from the total weight), moisture (oven drying method), and minerals (inductively coupled plasma atomic emission spectroscopy) contained in the cheese powder were also analyzed. Notably, the diets listed in Table 1 were formulated by modifying the composition of the AIN-76 diet. Specifically, the control diet was prepared by adding acid casein at $20 \%$ and butter oil at $19.82 \%$ to adjust fat content to $20 \%$. On the other hand, the cheese diet contained $39.06 \%$ of the cheese powder to make protein content equal to that of the control diet, and then butter oil 
was added to adjust the fat content to $20 \%$. The amounts of sodium, potassium, calcium, magnesium, phosphorus, and iron were adjusted to be equal between the control and cheese diets so that the nutrient composition was identical.

\subsection{Animals}

Male Fischer-344 rats (4 weeks of age) were purchased from Charles River Japan (Yokohama, Japan) and maintained in stainless-steel cages under controlled

Table 1 Composition of the control and cheese diets used in this study (g.100 g ${ }^{-1}$ )

\begin{tabular}{|c|c|c|}
\hline Component & Control & Cheese \\
\hline Cheese powder ${ }^{\mathrm{a}}$ & - & 39.06 \\
\hline Casein $^{\mathrm{b}}$ & 20.00 & - \\
\hline Butter oil ${ }^{\mathrm{c}}$ & 19.90 & 3.10 \\
\hline Cellulose & 5.00 & 5.00 \\
\hline Sucrose & 49.52 & 46.93 \\
\hline DL-methionine & 0.30 & 0.30 \\
\hline Vitamin mixture (AIN-76) ${ }^{\mathrm{d}}$ & 1.00 & 1.00 \\
\hline Mineral mixture $(\mathrm{AIN}-76)^{\mathrm{e}}$ & 3.50 & - \\
\hline Mineral mixture (for cheese) $)^{f}$ & - & 3.50 \\
\hline $\mathrm{NaCl}$ & 0.778 & - \\
\hline $\mathrm{CaHPO}_{4}$ & - & 0.260 \\
\hline $\mathrm{KH}_{2} \mathrm{PO}_{4}$ & - & 0.717 \\
\hline $\mathrm{K}_{2} \mathrm{CO}_{3}$ & - & 0.041 \\
\hline $\mathrm{MgO}$ & - & 0.057 \\
\hline $\mathrm{FeC}_{6} \mathrm{H}_{5} \mathrm{O}_{7}$ & - & 0.022 \\
\hline Total energy (kcal.100 $\mathrm{g}^{-1}$ ) & 454 & 462 \\
\hline Protein ( $\%$ of total energy) & 15.4 & 15.2 \\
\hline Fat ( $\%$ of total energy) & 39.7 & 39.0 \\
\hline Carbohydrate ( $\%$ of total energy) & 44.9 & 45.9 \\
\hline Calcium (mg.100 g ${ }^{-1}$ ) & 520 & 520 \\
\hline
\end{tabular}

Experimental diets were based on the AIN-76 formula with slight modifications. The protein $(17.5 \%, w / w)$ and fat $(20.0 \%, w / w)$ contents were adjusted to become equal between the control and cheese diets

${ }^{a}$ Cheese powder $(\%, w / w): 44.8 \%$ protein $(N \times 6.38$, IDF's recommended conversion factor for milk protein), $43.3 \%$ fat, $6.3 \%$ ash, and $1.0 \%$ water

${ }^{\mathrm{b}}$ Acid casein (Oriental Yeast Co., Ltd., Tokyo, Japan) $(\%, w / w): 87.5 \%$ protein $(N \times 6.38), 0.9 \%$ fat, $1.8 \%$ ash, and $9.8 \%$ water

${ }^{\mathrm{c}}$ Butter oil (Murray Goulburn Co-operative Co., Ltd., Melbourne, Australia) (\%, w/w): 99.6\% fat

${ }^{\mathrm{d}}$ Vitamin mixture contains choline bitartrate

${ }^{\mathrm{e}}$ Mineral mixture (AIN-76) (\%, w/w): $50.00 \% \mathrm{CaHPO}_{4} \cdot 2 \mathrm{H}_{2} \mathrm{O}, 7.40 \% \mathrm{NaCl}, 22.00 \% \mathrm{~K}_{3} \mathrm{C}_{6} \mathrm{H}_{5} \mathrm{O}_{5} \cdot \mathrm{H}_{2} 0,5.20 \%$ $\mathrm{K}_{2} \mathrm{SO}_{4}, 2.40 \% \mathrm{MgO}, 0.35 \% \mathrm{MnCO}_{3}, 0.60 \% \mathrm{FeC}_{6} \mathrm{H}_{5} \mathrm{O}_{7}, 0.16 \% \mathrm{ZnCO}_{3}, 0.055 \% \mathrm{CrK}\left(\mathrm{SO}_{4}\right)_{2} \cdot 12 \mathrm{H}_{2} \mathrm{O}, 0.03 \%$ $\mathrm{CuCO}_{3} \mathrm{Cu}(\mathrm{OH})_{2} \cdot \mathrm{H}_{2} \mathrm{O}, 0.001 \% \mathrm{Na}_{2} \mathrm{SeO}_{3} \cdot 5 \mathrm{H}_{2} \mathrm{O}, 0.001 \% \mathrm{KIO}_{3}$, and $11.803 \%$ sucrose

${ }^{\mathrm{f}}$ Mineral mixture (for cheese) (\%, w/w): $5.20 \% \mathrm{~K}_{2} \mathrm{SO}_{4}, 0.35 \% \mathrm{MnCO}_{3}, 0.16 \% \mathrm{ZnCO}_{3}, 0.055 \%$ $\mathrm{CrK}\left(\mathrm{SO}_{4}\right)_{2} \cdot 12 \mathrm{H}_{2} \mathrm{O}, 0.03 \% \mathrm{CuCO}_{3} \mathrm{Cu}(\mathrm{OH})_{2} \cdot \mathrm{H}_{2} \mathrm{O}, 0.001 \% \mathrm{Na}_{2} \mathrm{SeO}_{3} \cdot 5 \mathrm{H}_{2} \mathrm{O}, 0.001 \% \mathrm{KIO}_{3}$, and $94.203 \%$ sucrose 
temperature, humidity, and lighting conditions $\left(23 \pm 2{ }^{\circ} \mathrm{C}\right.$ temperature, $50 \pm 5 \%$ humidity, and 12-h light-dark cycle) in accordance with the animal experimentation regulations of the Milk Science Research Institute of Megmilk Snow Brand Co., Ltd., which are based on the guidelines proposed by the Science Council of Japan. The experimental protocol was registered under the number 090122-Higurashi. After a 1-week acclimatization period, during which the rats were feed the control diet, blood samples were collected from the cervical vein after $17 \mathrm{~h}$ of fasting. The blood samples were centrifuged to separate the serum, and the concentrations of serum triglyceride, total cholesterol, and HDL cholesterol were measured using a biochemical auto analyzer DRICHEM 7000V (FUJIFILM Medical Co., Ltd., Tokyo, Japan). Using these parameters, 14 rats were selected based on their almost identical mean body weight and concentration of serum triglycerides and cholesterol, split into two groups $(n=7)$, and fed either the control diet or the cheese diet for 9 weeks by pair-feeding. On the final day, all rats were sacrificed under anesthesia after $4 \mathrm{~h}$ of fasting. Serum and liver tissue samples were collected and stored at $-80{ }^{\circ} \mathrm{C}$ until analysis, and the white adipose tissues were removed and weighed.

\subsection{Biochemical analysis}

Blood samples were collected after $17 \mathrm{~h}$ of fasting every 2 weeks after the initiation of the feeding regimen, and serum triglyceride, total cholesterol, HDL cholesterol, and glucose levels were measured using a biochemical auto analyzer. Non-HDL cholesterol was calculated by subtracting HDL cholesterol from the total cholesterol. The adiponectin concentration in the serum sample collected on the final day was measured using an ELISA kit (Otsuka Pharmaceutical Co. Ltd., Tokyo, Japan).

\subsection{Liver lipid analysis}

Total liver lipids were extracted using the method outlined by Folch et al. (1957). Total cholesterol and triglyceride concentrations in the liver were measured with the cholesterol $\mathrm{E}$ test and the triglyceride $\mathrm{E}$ test, both of which are enzymatic colorimetric methods (purchased from Wako Pure Chemicals, Osaka, Japan).

\subsection{Fecal analysis}

Rats were transferred to metabolic cages, and feces samples were collected for 3 days during week 4 and week 8 of the experiment. After the feces samples were freeze-dried, the total lipid concentration was determined gravimetrically (Deuchi et al. 1994). Further, fecal sterol was extracted with hot ethanol, and the fecal cholesterol in the extracted lipid was determined using the cholesterol E test (Wako Pure Chemicals, Osaka, Japan).

\subsection{Statistical analysis}

Data are presented as the mean \pm standard error. Statistical analyses were performed using two-way repeated-measures ANOVA to assess differences between the diet groups and changes over time, and Welch's $t$ test to test differences between the groups. 
All statistical analyses were performed with EZR (Saitama Medical Center, Jichi Medical University, Saitama, Japan), which is a graphical user interface for $\mathrm{R}$ ( $\mathrm{R}$ Foundation for Statistical Computing, Vienna, Austria). More precisely, it is a modified version of an $\mathrm{R}$ commander designed to add statistical functions frequently used in biostatistics (Kanda 2013). Differences were considered significant at $P<0.05$ and a statistical tendency at $0.05 \leq P<0.10$.

\section{Results}

\subsection{Growth parameters}

The effect of cheese consumption on various growth parameters is presented in Table 2. After 9 weeks of cheese diet consumption, there were no significant differences in body weight, diet intake, liver weight, or adipose tissue weight compared to the rats fed the control diet. Body weight gain and the food efficiency ratio tended to be higher in the cheese group than in the control group ( $P=0.065$ and $P=0.099$, respectively).

\subsection{Serum lipid and adiponectin concentrations}

The concentrations of serum triglycerides, total cholesterol, HDL cholesterol, and nonHDL cholesterol were measured every 2 weeks. Two-way repeated-measures ANOVA revealed that the main effect of diet on HDL cholesterol resulted in a statistical tendency (Fig. 1c, $P=0.086$ ) and that on non-HDL cholesterol was significant (Fig. 1d, $P=0.013$ ). In all the serum parameters examined, the main effect of time

Table 2 Body weight, diet intake, liver weight, abdominal adipose tissue weights, and serum adiponectin concentration in rats fed control or cheese diet for 9 weeks

\begin{tabular}{llll}
\hline & Control & Cheese & $\begin{array}{l}P \text { values } \\
\text { (Welch's } t \text { test) }\end{array}$ \\
\hline Initial body weight (g) & $62.05 \pm 1.04$ & $62.86 \pm 0.80$ & 0.546 \\
Final body weight (g) & $179.79 \pm 3.05$ & $186.85 \pm 2.57$ & 0.103 \\
Body weight gain (g) & $117.74 \pm 2.43$ & $124.00 \pm 1.87$ & 0.066 \\
Diet intake (g.day ${ }^{-1}$ ) & $7.95 \pm 0.08$ & $8.12 \pm 0.05$ & 0.106 \\
Food efficiency ratio (g gain.100 $\mathrm{g}^{-1}$ intake) & $26.44 \pm 0.34$ & $27.27 \pm 0.32$ & 0.099 \\
Liver weight $\left(\mathrm{g} .100 \mathrm{~g}^{-1}\right.$ body weight) & $3.20 \pm 0.16$ & $2.88 \pm 0.09$ & 0.116 \\
White adipose tissue weight (g.100 $\mathrm{g}^{-1}$ body weight) & & \\
$\quad$ Mesenteric & $2.41 \pm 0.08$ & $2.62 \pm 0.12$ & 0.164 \\
Epididymal & $3.08 \pm 0.11$ & $3.13 \pm 0.12$ & 0.728 \\
Retroperitoneal & $1.95 \pm 0.10$ & $2.02 \pm 0.08$ & 0.599 \\
Perinephric & $0.82 \pm 0.04$ & $0.82 \pm 0.04$ & 0.930 \\
Total & $8.25 \pm 0.28$ & $8.59 \pm 0.28$ & 0.405 \\
Adiponectin $\left(\mu \mathrm{g} . \mathrm{mL}^{-1}\right.$ ) & $6.96 \pm 0.74$ & $9.93 \pm 0.94$ & 0.030 \\
\hline
\end{tabular}

Values are mean $\pm \mathrm{SE}, n=7$ 

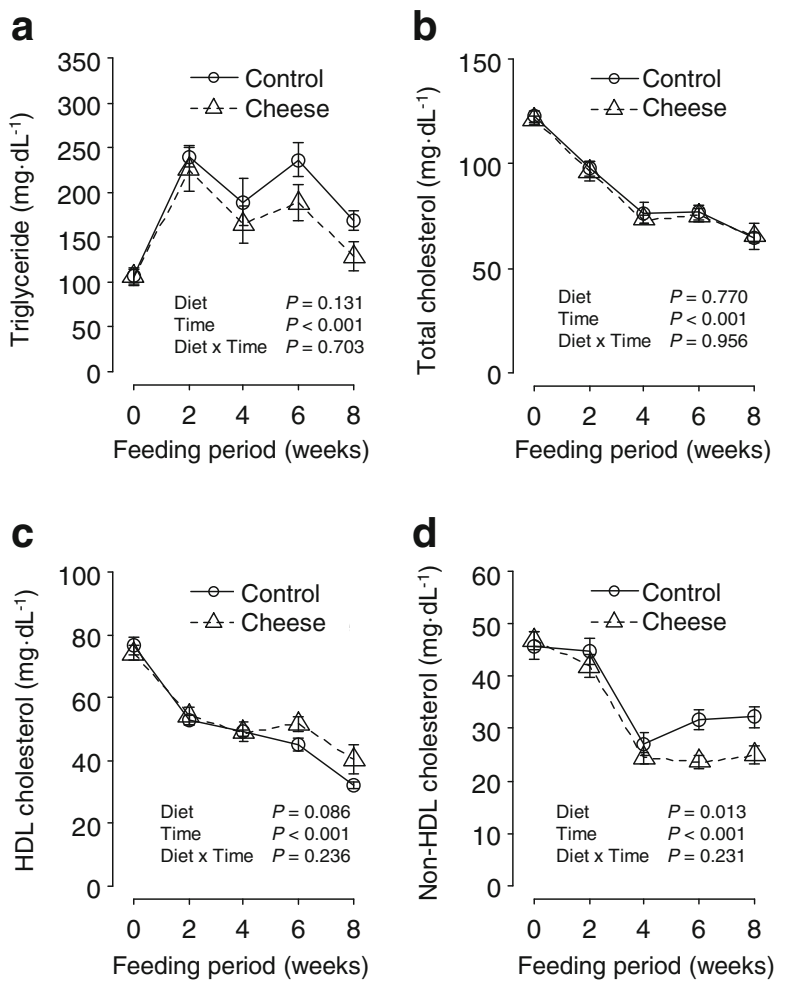

Fig. 1 Changes in the serum concentrations of triglyceride (a), total cholesterol (b), high-density lipoprotein $(H D L)$ cholesterol (c), and non-HDL cholesterol (d) measured using a biochemical auto analyzer. Measurements were taken every 2 weeks while the rats were fed the control or cheese diet. Values are the mean \pm standard error ( $n=7$ rats per group). Data were analyzed by two-way repeated-measures ANOVA (diet, time, and diet $\times$ time)

was significant $(P<0.001)$, and the diet-by-time interaction was not significant. Moreover, the serum adiponectin concentration on the final day of this study was significantly higher in the cheese group compared to the control group (Table 2).

\subsection{Accumulation of triglycerides and cholesterol in the liver}

The effect of cheese consumption on lipid accumulation in the liver was evaluated (Fig. 2). Our results have shown that the concentrations of triglycerides and cholesterol in the liver were significantly lower in the cheese group compared to the control group 9 weeks after the initiation of the experiment $(P=0.016$ and $P<0.001$, respectively).

\subsection{Fat excretion in the feces}

To determine the effect of cheese on fecal fat excretion, the amount of fat excreted in the feces was measured for rats fed the cheese and control diets and compared (Table 3). Two-way repeated-measures ANOVA revealed the main effect of diet resulted in a statistical tendency in the dry fecal weight $(P=0.052)$, and significant in the total fat $(P<0.001)$ and in the cholesterol content in the feces $(P=0.004)$. In the 

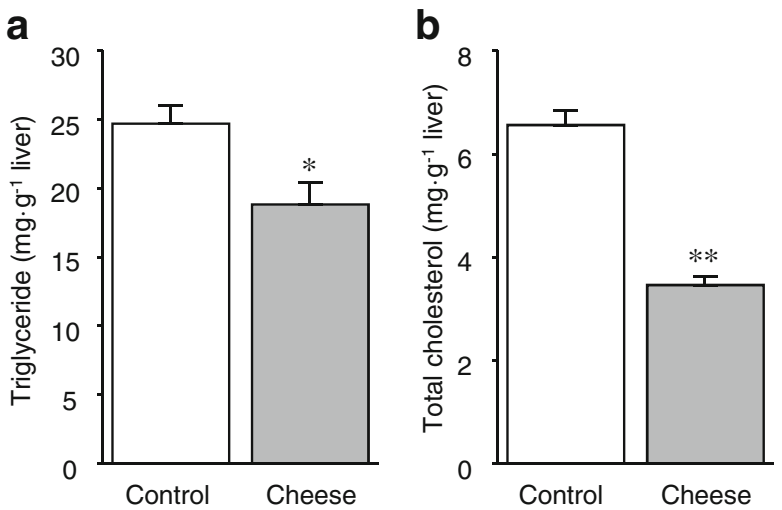

Fig. 2 Liver triglyceride (a) and total cholesterol (b) concentrations in rats fed a control or cheese diet. Values are the mean \pm standard error ( $n=7$ rats per group). Asterisks indicate significant differences between groups $(* P<0.05, * * P<0.01$, Welch's $t$ test, compared with the control group)

cholesterol in the feces, the main effect of time and the diet-by-time interaction were also significant $(P=0.023$ and $P=0.017$, respectively), with post hoc test revealing significant differences between the groups at both 4 and 8 weeks $(P=0.040$ and $P=0.002$, respectively).

\section{Discussion}

In the present study, we have shown that cheese intake reduces hepatic triglycerides and cholesterol concentrations in rats fed a high-fat diet. Despite the mechanisms underlying cheese-related health benefits being poorly understood, several researchers have indicated that cheese intake can improve obesity- and cardiovascular-related diseases (Elwood et al. 2010; Fumeron et al. 2011); therefore, we believe that reduced fat accumulation in the liver could play an important role in the downstream health benefits. For example, non-alcoholic fatty liver disease (NAFLD), the most frequent

Table 3 Fecal fat excretion in rats fed the cheese or control diet for 4 and 8 weeks

\begin{tabular}{|c|c|c|c|c|c|c|c|}
\hline & \multicolumn{2}{|l|}{4 weeks } & \multicolumn{2}{|l|}{8 weeks } & \multicolumn{3}{|c|}{$\begin{array}{l}P \text { values (two-way } \\
\text { repeated-measures } \\
\text { ANOVA) }\end{array}$} \\
\hline & Control & Cheese & Control & Cheese & Diet & Time & Diet $\times$ time \\
\hline $\begin{array}{l}\text { Dry weight } \\
\left(\text { g.day }^{-1}\right)\end{array}$ & $0.62 \pm 0.05$ & $0.70 \pm 0.02$ & $0.61 \pm 0.04$ & $0.77 \pm 0.06$ & 0.052 & 0.353 & 0.211 \\
\hline 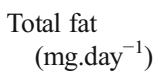 & $103.11 \pm 9.26$ & $182.97 \pm 10.72$ & $93.80 \pm 9.18$ & $209.03 \pm 20.52$ & $<0.001$ & 0.457 & 0.130 \\
\hline $\begin{array}{l}\text { Cholesterol } \\
\quad\left(\mathrm{mg}^{-} \text {day }^{-1}\right)\end{array}$ & $3.75 \pm 0.39$ & $5.06 \pm 0.42 *$ & $3.71 \pm 0.42$ & $6.60 \pm 0.58^{*}$ & 0.004 & 0.023 & 0.017 \\
\hline
\end{tabular}

Values are mean $\pm \mathrm{SE}, n=7$

*Significantly different from the control group $(P<0.05$, Welch's $t$ test) 
liver disease worldwide and an important marker of obesity-related diseases, such as metabolic syndrome and cardiovascular diseases, could possibly be treated or reduced to some extent following the cheese-mediated decrease in liver fat. It has also been reported that the presence of fat deposition in the liver is a crucial marker of multi-organ insulin resistance, independent of obesity, indicating that decreasing the levels of fat in the liver by increasing cheese intake could also be beneficial in treating insulin-related health issues (Fabbrini et al. 2009).

Notably, serum lipid abnormalities, such as high concentrations of triglyceride and total cholesterol along with a low concentration of HDL cholesterol, are known as conventional predictors of cardiovascular disease and are closely associated with fat accumulation in the liver (Targher et al. 2008). In this study, there were favorable changes in the HDL cholesterol and non-HDL cholesterol (the sum of intermediate-density lipoprotein, LDL, and VLDL cholesterol) concentrations in the serum of rats fed cheese diet. Previously, several studies have shown that cheese intake improves serum lipid metabolism, and a positive association between cheese intake and HDL cholesterol has also been observed in some cross-sectional analyses (Høstmark et al. 2009). In fact, cheese intake also appears to be linked to low levels of LDL cholesterol in the blood, particularly in comparison to butter intake, in human subjects (Biong et al. 2004; Hjerpsted et al. 2011; Nestel et al. 2005; Tholstrup et al. 2004), a trend which is reflected in the present study in rats.

In addition to changes in the serum parameters, elevated fecal fat excretion was also observed in the cheese group, which may be a possible explanation for the reduced fat accumulation in the liver following cheese consumption. Fat accumulation in the liver arises from several factors, including excess fatty acid inflow to the liver from adipose tissue and imbalance between lipogenesis and lipid oxidation (Donnelly et al. 2005). If higher levels of fat are being excreted following ingestion, then less is available for accumulation in bodily tissues. Notably, the effect of cheese on fecal fat excretion may appear in a relatively short period of time, with increases in fecal fat excretion occurring as early as 4 days in rats fed the cheese diet (data not shown).

We believe it is also possible that this effect is a consequence of the starter lactic acid bacteria used in the cheese manufacturing process. Indeed, several researchers have focused on the beneficial effects of lactic acid bacteria in fermented products, and it appears that some lactic acid bacteria, including probiotic ones, can bind to bile acids and increase their excretion, thereby resulting in decreased bile acid recycling in the enterohepatic circulation system and inhibited micelle formation in the gut (St-Onge et al. 2000). In addition, Lactobacillus gasseri SBT2055, a probiotic lactic acid bacterium with antiobesity properties (Kadooka et al. 2010), has also been suggested to interrupt absorption of lipids in the intestine of rats by binding directly to cholesterol and fatty acids (Hamad et al. 2009; Usman and Hosono 1999). These findings suggest that lactic acid bacteria used to produce cheese may play a significant role in the downstream effects of cheese consumption; however, additional research is warranted to examine these relationships.

Furthermore, it is also possible that calcium derived from cheese is responsible for the observed increase in fecal fat excretion. Although the calcium content was adjusted to an equal amount between the experimental diets in this study, the types of calcium contained in the diets might be different from each other. Calcium derived from dairy foods is known to be present as a form of micellar calcium phosphate, and has a higher bioavailability than other forms of calcium (Holt 1992; Wong and LaCroix 1980). The amount of soluble calcium in the small intestinal contents of rats fed a diet containing a 
micellar calcium phosphate-phosphopeptide complex was shown to be higher than that of rats fed a control diet containing whey calcium and casein phosphopeptides as separate ingredients (Toba et al. 1999). It is known that soluble calcium interacts with fatty acids, resulting in the formation of insoluble calcium-fatty acid soaps and reduced fat absorption (Teegarden 2005). Thus, it is possible that calcium derived from cheese can easily form calcium-fatty acid soaps in the small intestine compared with other forms of calcium. Consistent with our findings, a recent intervention trial performed by Soerensen et al. (2014) showed milk- and cheese-based diets increased fecal fat excretion compared with non-dairy diet, and they pointed out that changes in fecal fat excretion were inversely correlated to those in LDL cholesterol concentration.

One of the final parameters we analyzed in this study was the concentration of adiponectin. Adiponectin, an adipose tissue-derived cytokine, is known to induce several beneficial metabolic actions, including increasing fatty acid beta oxidation, improving hepatic insulin sensitivity, and mediating anti-inflammatory effects (Kaser et al. 2005). Adiponectin receptors expressed on liver cells have also been shown to mediate the activation of AMP kinase and peroxisome proliferator-activated receptor alpha pathways, and malfunction of these signaling cascades plays a critical role in the development of NAFLD/non-alcoholic steatohepatitis (NASH) (Kaser et al. 2005). Indeed, it was reported that decreased levels of circulating adiponectin in NAFLD are related to hepatic insulin resistance and to the amount of hepatic fat content (Bugianesi et al. 2005). Infusion of adiponectin, on the other hand, appears to improve hepatic steatosis and several parameters related to metabolic syndrome in NASH in an obese mouse model as well as in alcoholic hepatitis in ethanol-fed mice (Xu et al. 2003). The present study highlighted a significant increase in serum adiponectin in the cheese group compared with the control group, suggesting that adiponectin signaling may function in the manifestation of cheese consumption-related health benefits.

It is also possible that the ripening process of the cheese could be responsible for the increase in adiponectin in the cheese-fed rats as several functional peptides are reported to be produced during ripening process and can influence adiponectin concentration (Saito et al. 2000). Furthermore, Higurashi et al. (2007) also demonstrated that an antioxidative peptide prepared from the cheese increased the production of adiponectin from visceral fat cells, suggesting that cheese peptides may contribute to the secretion of adiponectin. Taking into account the fact that the amount of cheese peptides produced depends on the degree of ripening of cheese, it is possible that healthpromoting effects of cheese could also be affected by the duration or the presence/ absence of the ripening process. Among a few studies focusing on the relationship between the ripening process of cheese and beneficial effects, Geurts et al. (2012) showed that longer-ripened camembert cheese improved glucose tolerance and hepatic steatosis in obese/diabetic mice. However, further investigation is needed to evaluate the contribution of bacterial metabolites such as peptides to the beneficial effects of cheese observed in our animal model.

\section{Conclusion}

Consumption of cheese reduces the accumulation of triglycerides and cholesterol in the liver of rats fed a high-fat diet and is accompanied by an improvement in serum 
lipoprotein profile as well as an increase in serum adiponectin concentration. Fat excretion in the feces was also increased following cheese consumption, which suggests that inhibition of fat absorption may play a role in mediating the beneficial effects of cheese. Taken together, these findings indicate that cheese has beneficial effects on lipid metabolism, and the reduction of liver fat accumulation is likely to be an important key in the mechanisms underlying these effects.

Acknowledgments All authors are employed by Megmilk Snow Brand Co., Ltd. We are grateful to Tomohiro Hosoya, Yoshikazu Morita, and Hiroaki Matsuyama (Megmilk Snow Brand Co., Ltd.) for their collaboration and useful suggestions. We are also grateful to Emiko Yamaguchi (YBS Co., Ltd.) for preparing the experimental diets and providing technical assistance.

\section{Compliance with ethical standards}

Conflict of interest The authors declare that they have no conflict of interest.

Institutional guidelines for the experimental animals The protocol was approved by the Animal Care and Use Committee of the Milk Science Research Institute of Megmilk Snow Brand Co., Ltd. Their guidelines are based on those of the Science Council of Japan.

\section{References}

Biong AS, Müller H, Seljeflot I, Veierød MB, Pedersen JI (2004) A comparison of the effects of cheese and butter on serum lipids, haemostatic variables and homocysteine. Br J Nutr 92:791-797

Bugianesi E, Pagotto U, Manini R, Vanni E, Gastaldelli A, de Iasio R, Gentilcore E, Natale S, Cassader M, Rizzetto M, Pasquali R, Marchesini G (2005) Plasma adiponectin in nonalcoholic fatty liver is related to hepatic insulin resistance and hepatic fat content, not to liver disease severity. J Clin Endocrinol Metab 90: 3498-3504

Deuchi K, Kanauchi O, Imasato Y, Kobayashi E (1994) Decreasing effect of chitosan on the apparent fat digestibility by rats fed on a high-fat diet. Biosci Biotechnol Biochem 58:1613-1616

Donnelly KL, Smith CI, Schwarzenberg SJ, Jessurun J, Boldt MD, Parks EJ (2005) Sources of fatty acids stored in liver and secreted via lipoproteins in patients with nonalcoholic fatty liver disease. J Clin Invest 115:1343-1351

Elwood PC, Pickering JE, Givens DI, Gallacher JE (2010) The consumption of milk and dairy foods and the incidence of vascular disease and diabetes: an overview of the evidence. Lipids 45:925-939

Fabbrini E, Magkos F, Mohammed BS, Pietka T, Abumrad NA, Patterson BW, Okunade A, Klein S (2009) Intrahepatic fat, not visceral fat, is linked with metabolic complications of obesity. Proc Natl Acad Sci U S A 106:15430-15435

Folch J, Lees M, Sloane Stanley GH (1957) A simple method for the isolation and purification of total lipids from animal tissues. J Biol Chem 226:497-509

Fumeron F, Lamri A, Emery N, Bellili N, Jaziri R, Porchay-Baldérelli I, Lantieri O, Balkau B, Marre M, DESIR Study Group (2011) Dairy products and the metabolic syndrome in a prospective study, DESIR. J Am Coll Nutr 30:454S-463S

Geurts L, Everard A, le Ruyet P, Delzenne NM, Cani PD (2012) Ripened dairy products differentially affect hepatic lipid content and adipose tissue oxidative stress markers in obese and type 2 diabetic mice. J Agric Food Chem 60:2063-2068

Hamad EM, Sato M, Uzu K, Yoshida T, Higashi S, Kawakami H, Kadooka Y, Matsuyama H, Abd El-Gawad IA, Imaizumi K (2009) Milk fermented by Lactobacillus gasseri SBT2055 influences adipocyte size via inhibition of dietary fat absorption in Zucker rats. Br J Nutr 101:716-724

Higurashi S, Kunieda Y, Matsuyama H, Kawakami H (2007) Effect of cheese consumption on the accumulation of abdominal adipose and decrease in serum adiponectin levels in rats fed a calorie dense diet. Int Dairy J 17:1224-1231 
Hjerpsted J, Leedo E, Tholstrup T (2011) Cheese intake in large amounts lowers LDL-cholesterol concentrations compared with butter intake of equal fat content. Am J Clin Nutr 94:1479-1484

Holt C (1992) Structure and stability of bovine casein micelles. Adv Protein Chem 43:63-151

Høstmark AT, Haug A, Tomten SE, Thelle DS, Mosdøl A (2009) Serum HDL cholesterol was positively associated with cheese intake in the Oslo Health Study. J Food Lipids 16:89-102

Kadooka Y, Sato M, Imaizumi K, Ogawa A, Ikuyama K, Akai Y, Okano M, Kagoshima M, Tsuchida T (2010) Regulation of abdominal adiposity by probiotics (Lactobacillus gasseri SBT2055) in adults with obese tendencies in a randomized controlled trial. Eur J Clin Nutr 64:636-643

Kanda Y (2013) Investigation of the freely available easy-to-use software "EZR" for medical statistics. Bone Marrow Transplant 48:452-458

Kang S, Davis RA (2000) Cholesterol and hepatic lipoprotein assembly and secretion. Biochim Biophys Acta 1529:223-230

Kaser S, Moschen A, Cayon A, Kaser A, Crespo J, Pons-Romero F, Ebenbichler CF, Patsch JR, Tilg H (2005) Adiponectin and its receptors in non-alcoholic steatohepatitis. Gut 54:117-121

Larsson SC, Crippa A, Orsini N, Wolk A, Michaëlsson K (2015) Milk consumption and mortality from all causes, cardiovascular disease, and cancer: a systematic review and meta-analysis. Nutrients 7:7749-7763

Nestel PJ, Chronopulos A, Cehun M (2005) Dairy fat in cheese raises LDL cholesterol less than that in butter in mildly hypercholesterolaemic subjects. Eur J Clin Nutr 59:1059-1063

Petyaev IM, Bashmakov YK (2012) Could cheese be the missing piece in the French paradox puzzle? Med Hypotheses 79:746-749

Saito T, Nakamura T, Kitazawa H, Kawai Y, Itoh T (2000) Isolation and structural analysis of antihypertensive peptides that exist naturally in Gouda cheese. J Dairy Sci 83:1434-1440

Soedamah-Muthu SS, Ding EL, Al-Delaimy WK, Hu FB, Engberink MF, Willett WC, Geleijnse JM (2011) Milk and dairy consumption and incidence of cardiovascular diseases and all-cause mortality: doseresponse meta-analysis of prospective cohort studies. Am J Clin Nutr 93:158-171

Soerensen KV, Thorning TK, Astrup A et al (2014) Effect of dairy calcium from cheese and milk on fecal fat excretion, blood lipids, and appetite in young men. Am J Clin Nutr 99:984-991

St-Onge MP, Farnworth ER, Jones PJ (2000) Consumption of fermented and nonfermented dairy products: effects on cholesterol concentrations and metabolism. Am J Clin Nutr 71:674-681

Targher G, Marra F, Marchesini G (2008) Increased risk of cardiovascular disease in non-alcoholic fatty liver disease: causal effect or epiphenomenon? Diabetologia 51:1947-1953

Teegarden D (2005) The influence of dairy product consumption on body composition. J Nutr 135:2749-2752

Tholstrup T, Høy CE, Andersen LN, Christensen RD, Sandström B (2004) Does fat in milk, butter and cheese affect blood lipids and cholesterol differently? J Am Coll Nutr 23:169-176

Toba Y, Kato K, Takada Y, Tanaka M, Nakano T, Aoki T, Aoe S (1999) Bioavailability of milk micellar calcium phosphate-phosphopeptide complex in rats. J Nutr Sci Vitaminol 45:311-323

Usman, Hosono A (1999) Viability of Lactobacillus gasseri and its cholesterol-binding and antimutagenic activities during subsequent refrigerated storage in nonfermented milk. J Dairy Sci 82:2536-2542

Wong NP, LaCroix DE (1980) Biological availability of calcium in dairy products. Nutr Rep Int 21:673-680

Xu A, Wang Y, Keshaw H, Xu LY, Lam KS, Cooper GJ (2003) The fat-derived hormone adiponectin alleviates alcoholic and nonalcoholic fatty liver diseases in mice. J Clin Invest 112:91-100 